\title{
Ein Patient hetzt seinen Hund auf mich
}

\begin{abstract}
Herr X war mir wenig sympathisch, was nicht unbedingt daran lag, dass er seinen fettleibigen Körper wenig wusch, sondern vielmehr daran, dass er seine Lebensgefährtin drangsalierte und schlug. Er hatte sogar schon wegen Körperverletzung im Gefängnis gesessen. Als er nun uns gegenüber wiederholt unstimmige Angaben gemacht hatte, teilte ich ihm mit, dass ich seinen Wünschen nicht nachkommen könne und er sich bitte einen anderen Hausarzt suchen möge.

Unabhängig davon besuchte ich die bettlägerige Mutter seiner Lebensgefährtin weiter. Wenn ich dort klingelte, wurde vor dem
\end{abstract}

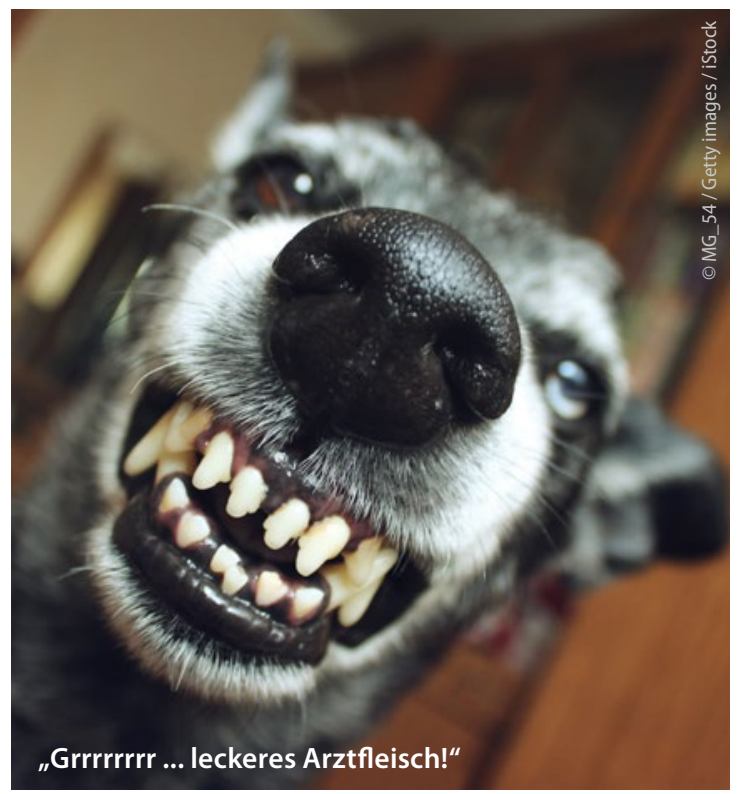

Öffnen der Tür der scharfe Schäferhund in den Abstellraum gesperrt. Eines Tages, ich stand am Krankenbett, kam nun der feine Herr $\mathrm{X}$ herein und öffnete dem Hund die Tür. Der ging, wie wohl erhofft, unmittelbar auf mich los. Ich riss der Mutter die Bettdecke weg und hielt sie wie einen Schutzschild vor mich - keine Sekunde zu früh! Der Hund biss zu, doch die Zähne drangen nicht hindurch. Die Tochter schrie laut und fing den fiesen Köter ein.

Ich erklärte, dass ich das Haus nur noch beträte, wenn Hund und Widerling nicht da wären. Das hat auch gut funktioniert.

Dr. Henrich Malz, Vlotho

\section{In seltenen Fällen sind Preußen ganz passabel}

Ein 67-jähriger Patient aus Niederbayern wurde wegen eines chronischen Schmerzsyndroms von seinem Orthopäden zur psychotherapeutischen Mitbehandlung in meine Praxis in München überwiesen. Obwohl ich, vor mehr als 30 Jahren aus Düsseldorf zugereist, den bayerischen Dialekt gut verstehe, musste ich doch bei diesem Patienten immer wieder mal nachfragen, ob ich seine Schilderung in originalem Niederbayerisch auch richtig verstanden hatte. Schließlich kommt es bei der hypnotherapeutischen Schmerztherapie auf die genaue Formulierung an, wenn man den Schmerz richtig verstehen will.
Geduldig „übersetzte“ er für mich manche Sätze ins Hochdeutsche. So kamen wir der Bedeutung seines Schmerzes langsam gemeinsam auf die Spur. Nachdem er einen Folgetermin ausgemacht hatte, schüttelte er mir zum Abschied heftig die Hand, wobei seine kräftige Holzarbeiterhand die meinige fast zerdrückte.

Dann sprach er die Worte: „Für an Preißn san se ganz gewand.“ Frei übersetzt: Für einen Preußen sind Sie ja ganz in Ordnung. Er verließ zufrieden die Praxis, und ich entschied mich, dies als Kompliment anzusehen.

Dr. Brigitte Zakaria, München

\section{Ungezwungenes Verhältnis zum eigenen Genitale}

Der zehnjährige Carlo hat akuten Mitteilungsdrang - und zum Glück einen heißen Draht zu seiner aufgeschlossenen und jugendlichen Oma. Häufig berichtet er ihr über seine Erlebnisse in der Schule und seinem Umfeld. Neulich musste er mal wieder sehr präzise sein. In seiner Schule hatte die Erstuntersuchung nach dem Jugendarbeitsschutzgesetz stattgefunden. Der Rapport an die Oma: „Stell Dir vor, ich hatte gestern eine ärztliche Untersuchung in der Schule. Der Schularzt war sehr gründlich. Er hat sogar meinen Sack abgetastet. Alles in Ordnung! Alles drin!"

Klare Worte, bei denen die Oma auch noch ernst bleiben sollte. Fazit: Die Zierde des Mannes ist nicht unantastbar.

Dr. Udo Fuchs, Hamburg 